\title{
Caracterização dos aspectos microbiológicos do Queijo Minas Artesanal de Monte Carmelo/MG
}

A região do Triângulo Mineiro é identificada como produtora de QMA e têm-se visto um número cada vez maior de produtores interessados em obter o cadastramento do IMA e com isso é necessário caracterizar o queijo elaborado para legalização esses produtores. O objetivo do trabalho foi avaliar os aspectos microbiológicos do Queijo Minas Artesanal de Monte Carmelo-MG em diferentes tempos de maturação, tanto de produtores cadastrados, quanto em fase de cadastramento. Foram coletadas 16 amostras de queijos, sendo quatro queijarias A, B, C e D, onde cada uma forneceu quatro amostras sendo elas 0 , 10 , 20 e 30 dias de maturação. O Staphylococcus spp. foi encontrado em contagens elevadas em todas as amostras, já o Staphylococcus coagulase positivo foi encontrado nas queijarias A, B e C. Salmonella spp. não foi isolada nas amostras de QMA em todos os períodos de maturação estudados. Em contrapartida, a Listeria spp. foi isolada em 6 diluições, das 48 analisadas, onde foi confirmado o gênero Listeria spp., porém, não foi confirmada a presença de Listeria monocytogenes nas 6 positivas. Dessa forma, além da determinação de um período mínimo de maturação de 15 dias, onde nessa fase todos os parâmetros estão abaixo do limite máximo permitido na legislação, faz-se necessários novos estudos para contínuo desenvolvimento do Triângulo Mineiro como região produtora, bem como para a melhoria dos queijos nela produzidos e padronização de tecnologia de fabricação visando a caracterização futura pelos órgãos responsáveis.

\section{Characterization of the microbiological aspects of the Minas Artesanal Cheese from Monte Carmelo/MG}

\begin{abstract}
The region of the Triangulo Mineiro is identified as a producer of QMA and an increasing number of producers interested in obtaining the registration of the IMA have been seen and it is therefore necessary to characterize the cheese prepared to legalize these producers. The objective of the study was to evaluate the microbiological aspects of the Minas Artesanal Cheese from Monte Carmelo-MG at different maturation times, both for registered producers and in the registration phase. 16 cheese samples were collected, four of which were A, B, C and D, where each one provided four samples, 0, 10, 20 and 30 days of maturation. Staphylococcus spp. was found in high counts in all samples, whereas the positive coagulase Staphylococcus was found in cheesemakers A, B and C. Salmonella spp. was not isolated in the QMA samples in all studied maturation periods. In contrast, Listeria spp. was isolated in 6 dilutions, of the 48 analyzed, where the genus Listeria spp. However, the presence of Listeria monocytogenes in the 6 positives was not confirmed. Thus, in addition to determining a minimum maturation period of 15 days, where in this phase all parameters are below the maximum limit allowed by law, further studies are necessary for the continued development of the Triângulo Mineiro as a producing region, as well as for the improvement of the cheeses produced there and standardization of manufacturing technology aiming at the future characterization by the responsible bodies.
\end{abstract}

Keywords: Microbiota of cheeses; Artisan cheeses; Cheese maturation.

Sthefania Dalva da Cunha Rezende ic Centro Universitário do Cerrado, Brasil http://lattes.cnpq.br/2988384474905850 http://orcid.org/0000-0003-1616-9743 sthenutri@hotmail.com

\section{Marlene Jeronimo (id}

Instituto Federal do Triângulo Mineiro, Brasil http://lattes.cnpq.br/1086831740131511 http://orcid.org/0000-0001-7707-7258

sthenutri@hotmail.com

Diego Cesar Veloso Rezende (ic)

Centro Universitário Mário Palmério, Brasil http://lattes.cnpq.br/2390623769547865 http://orcid.org/0000-0001-6176-0220 diegoformiga@yahoo.com.br

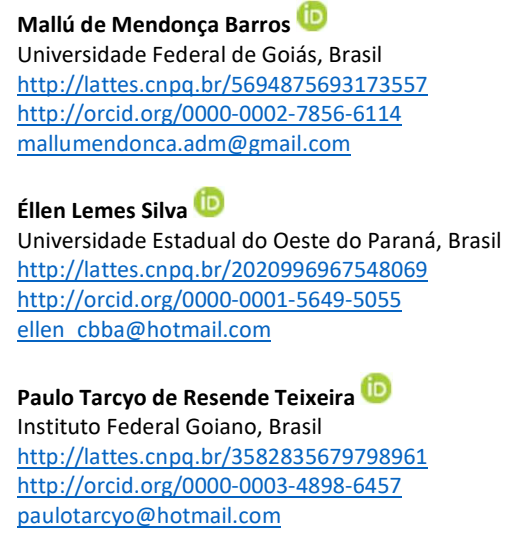

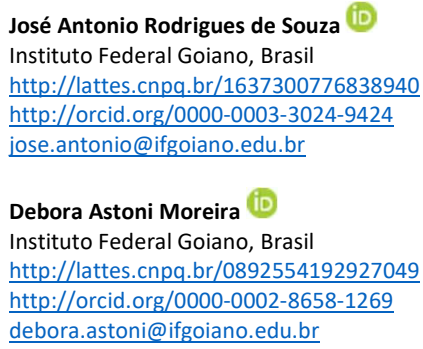

Referencing this:

REZENDE, S. D. C.; JERONIMO, M.; REZENDE, D. C. V.; BARROS, M. M.; SILVA, É. L.; TEIXEIRA, P. T. R.; SOUZA, J. A. R.; MOREIRA, D. A.. Caracterização dos aspectos microbiológicos do Queijo Minas Artesanal de Monte Carmelo/MG. Revista Ibero Americana de Ciências Ambientais, v.11, n.6, p.621-637, 2020. DOI: 


\section{INTRODUÇÃO}

De acordo com Chalita et al. (2009), o mercado de queijos especais no Brasil, tem sido impulsionado por um aumento de vendas no varejo, mas também devido ao crescimento expressivo no food service, o que representa aumento do consumo de 50 tipos de queijo, dentre eles, 234 marcas de queijo prato, 353 de muçarela, 263 de minas frescal. Em 2007, foram exportadas 7,58 mil toneladas de queijo, sendo o Brasil o sexto maior produtor de queijos do mundo.

Não apenas os queijos industrializados, mas o ritmo também acompanha os Queijos Artesanais de Minas, produzidos a partir do leite cru, e compõem um conjunto simbólico abrangente e complexo que é tradição, tradução da terra e da cultura das Minas Gerais. Sua produção envolve um espaço físico natural, mas que tem muito mais do tempo e da história do que se pode imaginar, cujo modo de produção nas propriedades rurais vem passando por várias gerações, desde que foi introduzido no Brasil, como herança da colonização portuguesa, logo "modo artesanal de fazer queijo de Minas" foi considerado Patrimônio Imaterial do Brasil em 2008, pelo Instituto do Patrimônio Histórico e Artístico Nacional - IPHAN (DINIZ, 2013; IPHAN, 2006).

Percebe-se que o Estado de Minas Gerais está na vanguarda no que se refere à regulamentação dos queijos artesanais, inclusive servindo de exemplo e motivação para que pequenos produtores de outros Estados se articulem quanto às necessidades de certificação. Exemplo dessa articulação é a Lei Estadual no 20.549 de 18 de dezembro de 2012. Esta dispõe sobre a produção e a comercialização dos queijos artesanais de Minas Gerais, que segundo o Governo do Estado, valoriza os produtores, e cria regras para a expansão do agronegócio familiar, sem se descuidar dos cuidados sanitários envolvidos na produção (MINAS GERAIS, 2012).

Nesse contexto, mais do que um fator cultural e histórico, a produção de Queijo Minas Artesanal é um negócio que promove renda, trabalho e o desenvolvimento regional. Em outras palavras, variados são os motivos que ensejam um diálogo em prol da produção com qualidade, haja vista que a busca por certificação desenha métodos e padrões na garantia do diferencial competitivo do produto. Há a definição de papéis gerenciais e controle do processo de produção e visam criar resultados em nível de excelência na gestão, nos processos de produção.

Segundo Falconi (2003), o controle da qualidade total é um sistema gerencial que reconhece aas necessidades das pessoas, estabelece padrões que atendam ao mercado e visa melhorar continuamente, a partir de uma visão estratégica e com base nos dados e nos fatos para que os erros identificados não se repitam pela mesma causa.

Isso porque, até então, a legislação vigente à época, a Lei Estadual 14.185/2002, atinha-se às normas e à identidade ao queijo artesanal. Com a chegada de novas normas, a Secretaria de Agricultura, Pecuária e Abastecimento de Minas Gerais e a EMATER-MG, lançaram o "Programa de Apoio aos Queijos Tradicionais de Fabricação Artesanal", que, além de buscar a melhoria da qualidade e da produtividade de todas as queijarias das regiões tradicionalmente produtoras, visa, objetivamente, a promoção e a valorização, do 
imenso potencial de mercado do queijo mineiro (EMATER, 2015).

Desde então, o Queijo Minas Artesanal pode ser produzido em toda Minas Gerais, mas as regiões do Cerrado, Serra do Salitre, Araxá, Canastra, Serro e Campo das Vertentes possuem o título de produtores tradicionais. Os queijos das regiões Canastra e Serro já possuem também o selo de Indicação Geográfica (IG) (EMATER, 2015).

Somada a essas microrregiões, foi homologada mais uma microrregião que englobam Uberlândia, Araguari, Cascalho Rico, Estrela do Sul, Indianópolis, Monte Alegre, Monte Carmelo, Nova Ponte, Romaria e Tupaciguara, formando a sexta microrregião produtora tradicional de Queijo Minas Artesanal do Estado, chamada região "Triângulo Mineiro", criada no ano de 2014, regulamentada e amparada pela Lei Estadual 14.185/02, com aproximadamente 1,3 mil produtores, sendo somente 12 cadastrados ou em fase de cadastramento (AMVAP, 2014).

No Estado de Minas Gerais, esta atividade artesanal é comprovadamente geradora de renda para as famílias com base em agricultura familiar e está presente em mais de 600 dos 853 municípios do Estado. Os Queijos Minas Artesanais fabricados diretamente na fazenda a partir de leite cru representam mais de 29 mil toneladas/ano e mantêm na atividade mais de 25 mil produtores, destes, 10.745 são produtores rurais das seis principais regiões tradicionais (DORES et al., 2012; EMATER, 2015).

Se por um lado, trabalhos junto aos produtores estão sendo realizados com resultados e avanços bem animadores visando à qualidade, segurança alimentar, geração e melhoria de renda e preservação da tradição histórica e cultural do QMA, por serem produzidos por meio do 'pingo', por outro lado, das sete microrregiões reconhecidas até o momento, em Minas Gerais, praticamente não há dados científicos sobre o queijo do Triângulo Mineiro. As outras microrregiões estão bem caracterizadas, quanto ao tipo de queijo, características gerais, condições sanitárias, produtor e comportamento do consumidor do QMA.

Em função de a atividade apresentar nível de informalidade conhecido, é sabido que a regulamentação recente desta região ainda traz questionamentos, pois não especifica como e quando serão feitos os estudos para definir os parâmetros físico-químicos e microbiológicos do Queijo Minas Artesanal.

Dentro desta perspectiva, este estudo objetivou estabelecer características microbiológicas do QMA da Microrregião do Triângulo Mineiro em unidades produtoras cadastradas ou em processo de cadastramento, adequadas às condições satisfatórias das Boas Práticas Agropecuárias (BPA) e Boas Práticas de Fabricação (BPF) segundo o IMA e EMATER, uma vez que estes parâmetros ainda não são estabelecidos.

\section{MATERIAIS E MÉTODOS}

\section{Localização e seleção das unidades produtoras de Queijo Minas Artesanal}

O estudo foi desenvolvido no município de Monte Carmelo-MG, que atualmente integra a região do Triângulo Mineiro, sendo produtora de Queijo Minas Artesanal conforme Portaria no 1397, de 13 de fevereiro de 2014. As visitas técnicas para coleta dos dados e das amostras foram realizadas com auxílio dos Extensionistas Agropecuários da Empresa Mineira de Assistência Técnica Rural (EMATER - MG). 
Inicialmente, foi realizada uma busca na lista de produtores cadastrados no Instituto Mineiro de Agropecuária (IMA), aliada a outros trabalhos realizados na microrregião por parte da EMATER. Embora existam vários outros produtores de QMA na microrregião do Triângulo Mineiro, este trabalho de pesquisa preconizou somente os cadastrados ou em fase final de cadastramento no IMA.

Das queijarias selecionadas para a realização deste estudo, 3 eram cadastradas e 1 em fase de cadastramento (Figura 1). Pôde-se verificar que as instalações são novas e adequadas às exigências do IMA, existe o controle de zoonoses do gado bem como o tratamento da água. Outro fator que beneficiou o trabalho foi a receptividade dos produtores e seu interesse em melhorar os produtos.

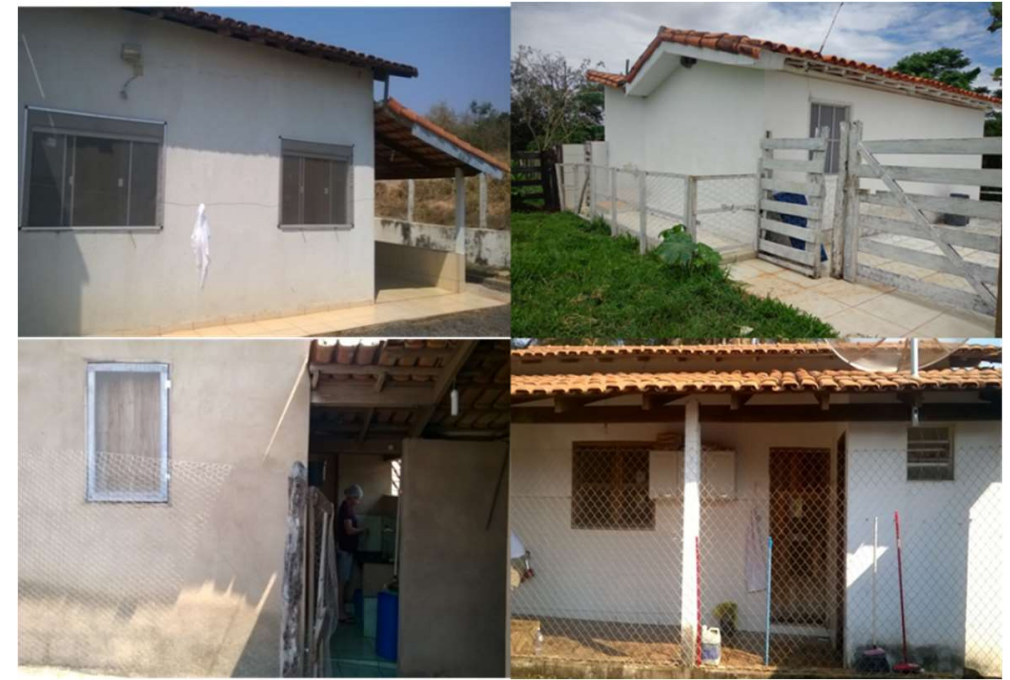

Figura 1: Apresentação das queijarias artesanais da microrregião do Triângulo Mineiro, selecionadas para a execução experimental.

Apesar de o queijo Minas artesanal ser produzido e comercializado em toda a região do Triângulo há mais de 40 anos, a iniciativa de cadastrar e reconhecer oficialmente as propriedades produtoras é recente, com início em 2012. Portanto, não se conhece as características de produção desses queijos e se o mesmo é fabricado em condições semelhantes aos produzido em regiões tradicionais, como a da Canastra, por exemplo, e ainda se os manipuladores possuem hábitos higiênicos que permitam que estes queijos atendam às normas preconizadas na Portaria no 523, de 3 de julho de 2002 (IMA, 2002) e Portaria no518 de 14 de junho de 2002 (IMA, 2002).

\section{Plano de amostragem}

Em levantamento inicial, foram encontradas somente três queijarias registradas com cadastro final, e outras seis em processo de registro inicial de acordo com o IMA, sendo este número ínfimo visto que a microrregião possui 10 municípios com mais de 1000 unidades produtoras vivendo na clandestinidade. Este número de produtores descredenciados na região, que apesar de muito promissora e em expansão, é explicado em parte pelo recente trabalho de órgãos como EMATER e IMA seja na área de pesquisas, qualificação ou inspeção e o trâmite burocrático para conseguir o cadastro final.

Foi levado em consideração o posicionamento de cada propriedade produtora de QMA que esteja dentro da microrregião do Triângulo Mineiro. E que por ocasião da execução deste, apenas quatro 
propriedades se encontravam aptas às exigências legais (representando o universo de dados analisados), todas elas instaladas no município de Monte Carmelo/MG.

As queijarias foram selecionadas por meio de amostragem intencional e a partir disso, foram realizadas as visitas técnicas às quatro propriedades identificadas. A unidade de amostragem deveria conter como requisito básico de fabricação do queijo, a utilização do tipo 'pingo' e com instalações adequadas para sua produção.

Justifica-se no presente estudo, que não foi realizada a coleta do mesmo lote para os quatro tempos de maturação devido aos custos dispendiosos tanto de tempo quanto financeiramente para a Instituição de Ensino, por este motivo, as coletas foram realizadas num só dia, fazendo a média dos queijos de cada queijaria visitada.

\section{Instalações das queijarias}

Entende-se por queijarias artesanais os estabelecimentos situados na propriedade rural, destinados exclusivamente à produção de queijos artesanais (MINAS GERAIS, 2002).

Nas visitas às instalações físicas dos locais destinados à fabricação do Queijo Minas Artesanal do Triângulo (Figura 2), observou-se que a maioria ainda apresenta inadequações em sua parte física por não apresentarem, principalmente fluxograma de fabricação condizente com a legislação, porém todas anualmente passam por processo de melhorias na sua parte física.

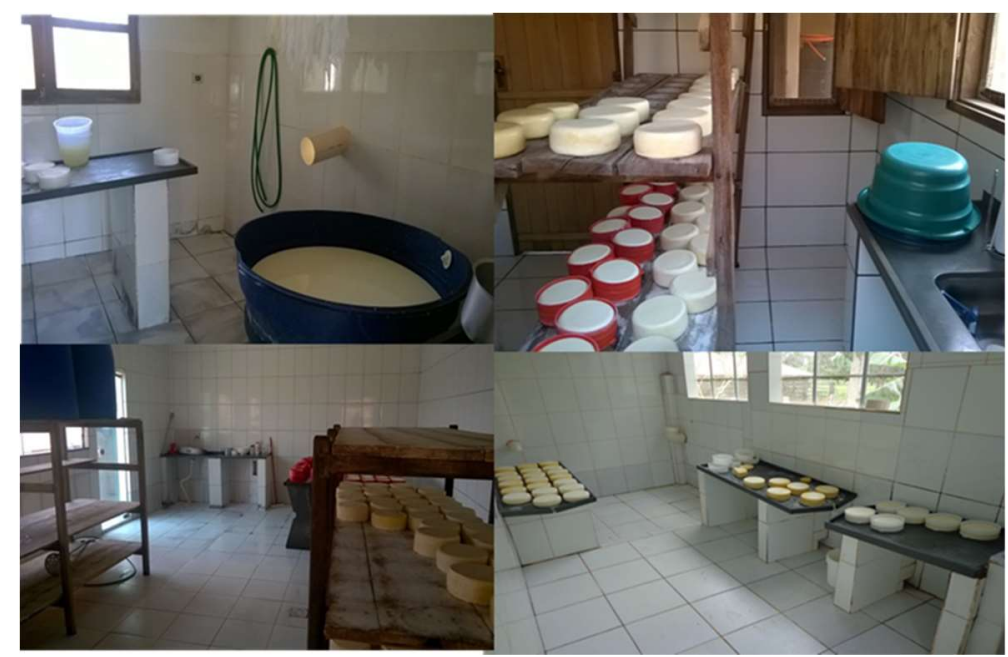

Figura 2: Instalações das queijarias objeto deste estudo.

Observou-se que a motivação principal em produzir o QMA veio após trabalho realizado pela EMATER na região, com o intuito de recuperar a tradição local do 'saber fazer' o queijo. Os produtores, alguns com histórico familiar de elaboração de outros tipos de queijo, como o frescal, consideram o QMA uma fonte segura de garantirem sua renda e atingirem mercados mais distantes.

\section{Análises estatísticas}

O experimento foi conduzido em Delineamento Inteiramente Casualizado (DIC), com as seguintes fontes de variação fixa: quatro propriedades rurais na microrregião do Triângulo em diferentes comunidades 
(4), quatro tempos de maturação (4), em 3 repetições para confirmação.

Os dados foram compilados em planilhas eletrônicas geradas no software Microsoft Excel, versão Windows 2007. Os resultados foram anotados e realizou-se a análise de variância e o Teste de Tukey $(p<0,05)$ além da análise de regressão, ambos realizadas no programa estatístico Sistema de Análise de Variância 'SISVAR' 5.5 Dex/UFLA. Quando o teste F deu significativo, foi feita a regressão linear ou quadrática, de acordo com cada resultado.

\section{Identificação das amostras e local de análises}

Cada amostra de queijo foi identificada com 3 dígitos: 10 dígito - representa a letra da queijaria, sendo A, B, C e D; 2o dígito - representa o tempo de maturação de cada queijo, sendo 0 (para 0 dias), 1 (para 10 dias), 2 (para 20 dias), e 3 (para 30 dias); 3o dígito - representa a diluição, caso fosse necessário, sendo diluição 1 (-1), 2 (-2) e 3 (-3). Ex: A01, B23, C21, D13.

\section{Coleta das amostras e local de análises}

Por se tratar de um produto artesanal ainda sem características definidas, o queijo é produzido com matéria-prima integral e não padronizada. O estudo acompanhou a fabricação, maturação, realizou a coleta, o transporte e as análises microbiológicas nos meses de agosto/setembro na microrregião do Triângulo Mineiro. Em cada queijaria foi adotado o seguinte procedimento: Fabricação dos queijos; Separação das amostras por queijaria e tempo; Maturação.

Para cada produtor foram separados e identificados os quatros queijos coletados por fabricação e retirados com 0, 10, 20 e 30 dias de maturação, respectivamente. Os queijos coletados foram embalados em sacos plásticos de PVC transparente, acondicionados em caixa isotérmica contendo formas de gel eutético para manter os queijos numa temperatura de refrigeração até o local de análise onde foram submetidos às análises físico-químicas e microbiológicas.

\section{Análises microbiológicas das amostras}

As amostras de queijos foram analisadas no Laboratório de Microbiologia do Instituto Federal do Triângulo Mineiro (IFTM) Campus Uberaba.

Os parâmetros microbiológicos estão de acordo com o Decreto no 44.864, de 01 de agosto de 2008 (MINAS GERAIS, 2008), que estabelece alguns parâmetros físico-químicos e microbiológicos para o queijo Minas Artesanal. Os parâmetros analíticos considerados neste decreto são os mesmos da legislação federal ( $R D C$ no 12, 2001) para queijos de alta umidade (acima 45,9\%), sendo os seguintes de acordo com a Tabela 1.

Tabela 1: Parâmetros microbiológicos no QMA.

\begin{tabular}{llc}
\hline Alimento & Microrganismo & Tolerância para amostra indicativa \\
\hline Queijo Minas Artesanal & Coliformes a $45^{\circ} \mathrm{C} / \mathrm{g}$ & $* 5 \times 10^{2} \mathrm{NMP} \cdot \mathrm{g}^{-1}$ \\
& Estaf.coag.positiva/g & $* 5 \times 10^{2} \mathrm{UFC} \cdot \mathrm{g}^{-1}$ \\
& Salmonellasp $/ 25 \mathrm{~g}$ & Aus \\
\hline
\end{tabular}


*Para queijos com 0 dias de maturação.

L.monocytogenes $/ 25 \mathrm{~g}$

Aus

Fontes: Minas Gerais (2008); Brasil (RDC no 12/ 2001).

\section{Coliformes Totais e Termotolerantes}

Para a análise de coliformes foi utilizado o método NMP, onde é um método clássico de contagem de coliformes totais, termotolerantes e E. coli em água e alimentos que significa o Número Mais Provável

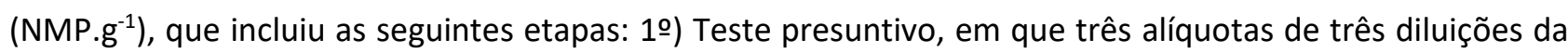
amostra de queijo são inoculadas em uma série de três tubos de Caldo Lauril Sulfato Triptose (LST) por diluição $\left(10^{-1}, 10^{-2}, 10^{-3}\right)$. O LST contém lactose e a observação de crescimento com produção de gás a partir da lactose, após 24-48h de incubação a 35ํㅡ, é considerada suspeita (presuntiva) da presença de coliformes; 2) Para a confirmação dos coliformes totais e termotolerantes, uma alçada de cada tubo suspeito é transferida para tubos de Caldo Verde Brilhante Bile 2\% (VB) e Caldo E. coli (EC), meios seletivos que contém lactose. A observação de crescimento com produção de gás nos tubos de VB, após 24-48h de incubação a 35 ํㅡ, é considerada confirmativa da presença de coliformes totais. Crescimento com produção de gás nos tubos de EC, após $24 \mathrm{~h}$ de incubação a 45,5으 (ou 44,5으, no caso de água), é considerada confirmativa da

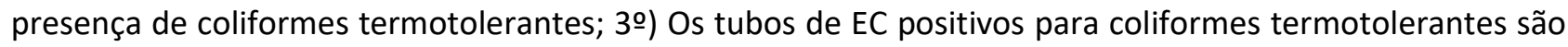
suspeitos da presença de E. coli.

\section{Staphylococcus aureus}

Para análise de Staphilococcus aureus foi utilizado o Kit analítico (petrifilm) oficializados pela AOAC (Association of Official Analytical Chemists) para a contagem de S. aureus em alimentos, sendo o 3M Microbiology Products Petrifilm ${ }^{T M}$ StaphExpress (AOAC, 2005). Esse tipo de petrifilm é utilizado principalmente para alimentos processados e preparados e produtos lácteos processados, como é o caso do Queijo Minas Artesanal.

Para o preparo da amostra e inoculação, foram pesados $10 \mathrm{~g}$ de amostra para $90 \mathrm{~mL}$ de Água Peptonada $0,1 \%\left(\mathrm{H}_{2} \mathrm{Op}\right)$ a $25^{\circ} \mathrm{C}$ e homogeneizadas. A partir dessa diluição inicial, foi preparada uma série de diluições decimais, utilizando-se o mesmo diluente.

Realizou-se três diluições $\left(10^{-1}, 10^{-2}, 10^{-3}\right)$ da amostra e inoculou-se $0,1 \mathrm{~mL}$ de cada diluição na superfície de placas de Petrifilm Stx, previamente preparadas. Espalhou-se o inóculo com uma alça bacteriológica, das placas de maior para as placas de menor diluição, até que todo o excesso de líquido fosse absorvido.

As placas foram incubadas a 37으; e após 24 horas, as colônias vermelho-violetas foram contadas como Staphylococcus spp. Quando se verificaram colônias de outra coloração, o disco de confirmação Petrifilm Staph Express TM foi utilizado, sendo consideradas positivas para S. aureus o microrganismo que, após uma a três horas a 370 C, produziram um halo rosado. Calculou-se a população, e os resultados foram expressos em unidades formadoras de colônias/g. 


\section{Listeria monocytogenes}

Para análise de Listeria monocytogenes foi utilizado o Placa Petrifilm EL oficializada pela AOAC (Association of Official Analytical Chemists) para a presença ou ausência de Listeria spp, sendo o 3M Microbiology Products Petrifilm ${ }^{\mathrm{TM}}$ Listeria Place (AOAC, 2005). A Placa Petrifilm EL detecta a maioria das espécies de Listeria ambiental, como Listeria monocytogenes, Listeria innocua e Listeria welshimeri.

Para o preparo da amostra e inoculação, foram pesados $10 \mathrm{~g}$ de amostra para $90 \mathrm{~mL}$ Água Peptonada $0,1 \%\left(\mathrm{H}_{2} \mathrm{Op}\right)$ a $25^{\circ} \mathrm{C}$ e homogeneizadas. A partir dessa diluição inicial, foi preparada uma série de diluições decimais, utilizando-se o mesmo diluente.

Realizou-se três diluições $\left(10^{-1}, 10^{-2}, 10^{-3}\right)$ da amostra e inoculou-se $3 \mathrm{~mL}$ de cada diluição na superfície de placas de Petrifilm Stx, previamente preparadas. Pipetou-se o inóculo e com um difusor, espalhou todo o líquido na marca redonda da placa.

As placas foram incubadas com o lado transparente para cima, em pilhas de 5 placas, por $28 \mathrm{~h} \pm 2 \mathrm{~h}$ 35 ํ \pm 1 1ำ. Após este período, unidades formadoras de colônias róseas-roxeadas foram contadas como positivo/presença de Listeria spp. Em cada placa. A confirmação de Listeria monocytogenes não foi realizada

\section{Salmonella spp.}

Para análise de Salmonella foi utilizado o $3 \mathrm{M}^{\mathrm{TM}}$ Petrifilm ${ }^{\mathrm{TM}}$ Salmonella Express Food Safety oficializados pela AOAC (Association of Official Analytical Chemists) para a presença ou ausência de Salmonela nas amostras (AOAC, 2005). Esse tipo de petrifilm é utilizado principalmente para alimentos processados e preparados e produtos lácteos processados, como é o caso do Queijo Minas Artesanal.

Foi feito inicialmente o Caldo de enriquecimento para Salmonella 3M Rappaport-Vassiliadis R10 (RV R10), sendo $37 \mathrm{~g}$ do caldo de para $1 \mathrm{~L}$ de água deionizada, onde foram distribuídos em frascos com $90 \mathrm{~mL}$ do meio e auto clavado. O Suplemento de Enriquecimento para Petrifilm Salmonella (SALX) foi feito pesando 0,5g e adicionou-se em $200 \mathrm{~mL}$ de água estéril. Posteriormente foi coberto com papel alumínio e levado à geladeira. Adicionou-se 4,5mL da solução do suplemento em $90 \mathrm{~mL}$ do caldo. Foram pesados $10 \mathrm{~g}$ da amostra e colocada em $90 \mathrm{~mL}$ do meio (caldo+suplemento), onde incubou a $41,5 \circ \mathrm{C}$ por $24 \mathrm{~h}$. Após as $24 \mathrm{~h}$, como a amostra é de alta carga, passou-se $0,1 \mathrm{ml}$ para o caldo Rapapport e incubou por mais 18 horas à $41,5 \circ \mathrm{C}$ para depois seguir para o Petrifilm.

Os Petrifilms foram hidratados com $2 \mathrm{~mL}$ de água destilada, e inseriu-se o difusor apenas para espalhar na circunferência. Aguardou-se aproximadamente 1 hora (onde gel ficou vermelho). E com uma alça bacteriológica, estriou-se no Petrifilm delicadamente carregando mais no início e fazendo estrias maiores no final. Logo após o Petrifilm foi fechado e incubado por $24 \mathrm{~h}$ a 41,5ํㅡ. Após este período não foi constatado nenhuma colônia nas 48 placas.

As análises foram realizadas assepticamente, com o uso de chama dentro de capelas de fluxo laminar, seguindo os protocolos oficiais de rotina do laboratório do Instituto Federal do Triângulo Mineiro. Os resultados obtidos foram considerados impróprios ao consumo humano quando eram positivos. 


\section{RESULTADOS E DISCUSSÃO}

A avalição quantitativa dos microrganismos exigidos pela Lei Estadual no 14.185, de 31 de janeiro de 2002 e sua alteração pelo Decreto Estadual no 44.864, de 10 de agosto de 2008 (MINAS GERAIS, 2002; 2008) é constituída por: coliformes totais, E. coli e Staphylococcus coagulase positiva foram realizadas (tabelas 13 e 14). Os resultados qualitativos para a presença em $25 \mathrm{~g}$ do queijo para Listeria monocytogenes e Salmonella spp., exigidos pela legislação (MINAS GERAIS, 2002) estão apresentados de forma descritiva no texto.

\section{Staphylococcus spp.}

Na presente pesquisa a contagem de estafilococos coagulase negativa (SCN) pode ser considerada bastante alta (Tabela 2) e esteve presente em praticamente em quase todas as 48 amostras de Queijo Minas Artesanal. Não foi possível estabelecer uma média geral de SCN, uma vez que diversas placas deram incontáveis em vários tempos de maturação.

Embora a legislação determine parâmetros de aceitação no queijo apenas para Staphylococcus coagulase positivo, sabe-se que algumas cepas coagulase negativo, incluídas nesta contagem total de Staphylococcus spp., são também capazes de produzirem enterotoxinas, representando um risco potencial a saúde do consumidor (CASTRO, 2015).

Em geral, a contagem de células requeridas para produção de enterotoxinas por essas estirpes varia entre $10^{5}$ a $10^{9} \mathrm{UFC}^{-1}{ }^{-1}$, e é suficiente para a ocorrência de intoxicação alimentar estafilocóccica (PICOLI et al., 2006).

Tabela 2: Contagem de Staphylococcus spp. (CN) e Staphylococcus aureus (CP) nos Queijos Minas Artesanais nas queijarias visitadas em Unidades Formadoras de Colônias $/ \mathrm{g}^{-1}$.

\begin{tabular}{|c|c|c|c|}
\hline Queijaria & Tempo de Maturação (dias) & $\begin{array}{l}\text { Coagulase Negativa } \\
\text { (contagem) }\end{array}$ & Coagulase Positiva \\
\hline \multirow{4}{*}{ A } & 0 & Incontáveis & $3 \times 10$ \\
\hline & 10 & $2 \times 10^{4}$ & $<1$ \\
\hline & 20 & $3 \times 10^{4}$ & $<1$ \\
\hline & 30 & $<1$ & $<1$ \\
\hline \multirow{4}{*}{ B } & 0 & $3 \times 10^{6}$ & $2 \times 10^{2}$ \\
\hline & 10 & $8 \times 10^{4}$ & $<1$ \\
\hline & 20 & $6 \times 10^{4}$ & $<1$ \\
\hline & 30 & $1,3 \times 10^{5}$ & $<1$ \\
\hline \multirow{4}{*}{ C } & 0 & $3,9 \times 10^{6}$ & $1 \times 10$ \\
\hline & 10 & Incontáveis & $<1$ \\
\hline & 20 & $5 \times 10^{6}$ & $<1$ \\
\hline & 30 & $7,5 \times 10^{5}$ & $<1$ \\
\hline \multirow{4}{*}{ D } & 0 & $2 \times 10^{6}$ & $<1$ \\
\hline & 10 & $6,5 \times 10^{6}$ & $<1$ \\
\hline & 20 & Incontáveis & $<1$ \\
\hline & 30 & $1,7 \times 10^{5}$ & $<1$ \\
\hline
\end{tabular}

De todas as queijarias analisadas, a queijaria A, foi a que apresentou a menor contagem de estafilococos coagulase negativa. Já a queijaria C, foi a que apresentou a maior quantidade da bactéria (Figura 3). Uma justificativa para este aumento é que a mesma utiliza uma forma de plástico que é colocada no fundo do queijo para marcar os queijos com o nome da queijaria, desta forma este é outro objeto muito manipulado e consequentemente mal higienizado que induz a maior contagem destes microrganismos. 


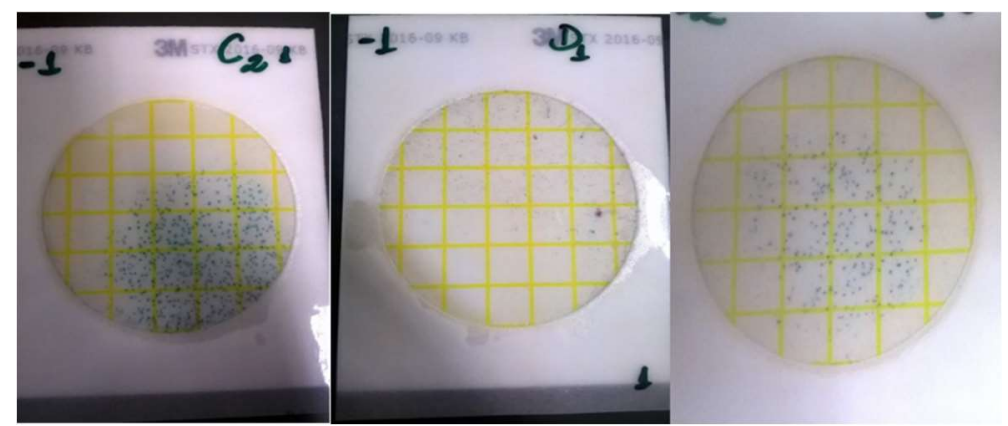

Figura 3: Resultados obtidos na análise de Staphylococcus spp. em diferentes queijarias.

Em um trabalho semelhante, a contagem média de Staphylococcus spp. em QMA da Serra da Canastra, maturado à temperatura ambiente, foi de $1,9 \times 10^{4} \mathrm{UFC}^{-g^{-1}}$, no período das chuvas, e de $3,2 \times 10^{3}$ UFC. $g^{-1}$, na seca, sendo as médias iguais $(p<0,05)$ (DORES et al., 2013).

Em trabalho realizado em Queijo Minas Artesanal elaborado na região da Serra da Canastra, a média nas propriedades cadastradas foi $1,2 \times 10^{8} \mathrm{UFC} . \mathrm{g}^{-1}$, e nas propriedades não cadastradas $2,1 \times 10^{8} \mathrm{UFC}^{-1} \mathrm{~g}^{-1}$ (RESENDE, 2010). Contagens semelhantes foram descritas em trabalho realizado em queijo Serra da Estrela, em que as contagens médias de Staphylococcus spp. variaram de $9,8 \times 10^{6}$ UFC. $g^{-1}$ a $5 \times 10^{7}$ UFC. $g^{-1}$, ao longo de 180 dias de maturação, quando o leite usado na produção não havia sido refrigerado (DAHL et al., 2000).

\section{Staphylococcus coagulase positiva}

Após a confirmação das colônias de Staphylococcus aureus pode-se afirmar que todas as amostras estão dentro dos padrões estabelecidos pela Agência Nacional de Vigilância Sanitária - ANVISA, conforme Resolução - RDC no 12, de 02 de janeiro de 2001, sendo o limite máximo tolerável de $10^{3} \mathrm{NMP}^{-1} \mathrm{~g}^{-1}$ (tabela 4).

Das amostras analisadas no trabalho sobre o Queijo Minas Artesanal do Triângulo Mineiro, a queijaria D foi a única unidade visitadas que não houve a presença de estafilococos coagulase positiva (25\%). Nas demais todos os queijos do tempo 0 dias apresentaram colônias e em especial a queijaria $C$ que também apresentou Staphylococcus aureus no tempo de 20 dias (Figura 4).

Outros trabalhos relativos ao QMA deram resultados bem superiores aos encontrados neste, onde trinta e três amostras (82,5\%) de Queijos Minas Artesanais da região do Serro apresentaram contagens de Staphylococcus coagulase positivo acima de $10^{3} \mathrm{UFC} . \mathrm{g}^{-1}$, estando impróprias ao consumo humano (BRANT et al., 2007). Este microrganismo foi o contaminante mais frequente, com contagem média de $1,2 \times 10^{6} \mathrm{UFC} . \mathrm{g}^{-1}$, sendo que 21 amostras (53\%) apresentaram contagens acima de $10^{5} \mathrm{UFC}^{-1}{ }^{-1}$. Neste caso, o risco de produção de enterotoxinas é existente. Ainda neste estudo, o queijo recém elaborado apresentou contagem média de $2,5 \times 10^{5}$ UFC. $g^{-1}$. Com a maturação por 30 dias do queijo, houve redução $(p<0,01)$ desta contagem para cerca de $1,3 \times 10^{4}$ UFC. $g^{-1}$ (BRANT et al., 2007). Os resultados deste experimento são similares aos relatados por Lubeck et al. (2001) que verificaram $100 \%$ das amostras de queijos coloniais da região do Paraná contaminadas com elevadas contagens de Staphylococcus aureus, sendo a contagem média encontrada de $5,9 \times 10^{5}$ UFC. $g^{-1}$. 


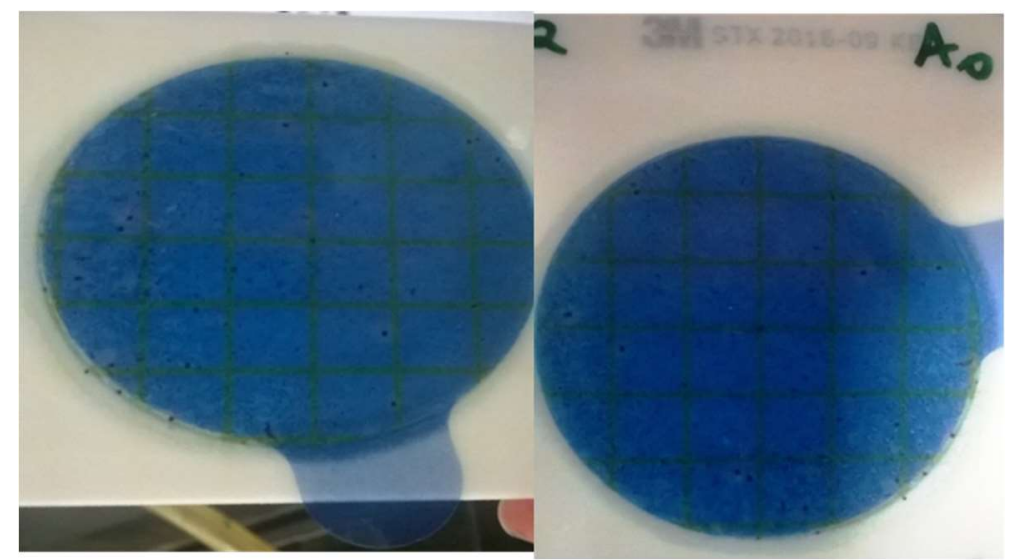

Figura 4: Resultados obtidos na análise de Staphylococcus aureus em diferentes queijarias, após a utilização do disco de confirmação.

O oposto foi descrito em QMA de Campo das Vertentes que apresentou contagens médias de Staphylococcus coagulase positivo de $1,1 \times 10^{5} \mathrm{UFC} . \mathrm{g}^{-1}$, no período das chuvas superior $(p<0,05)$ a contagem

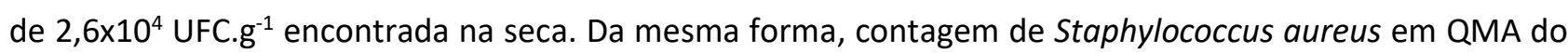
Serro, aos 8 dias de maturação, de $2,5 \times 10^{3} \mathrm{UFC} \cdot \mathrm{g}^{-1}$ nas águas foi superior a contagem encontrada de $1,1 \times 10^{2}$ UFC. $g^{-1}$ na seca (MARTINS, 2006).

Trinta e seis das 108 (33,33\%) amostras analisadas de queijo Serrano exibiram contagens de Staphylococcus aureus acima de $10^{3} \mathrm{UFC} . \mathrm{g}^{-1}$, valor estabelecido como máximo pela legislação vigente para Staphylococcus coagulase positivo. Foi observada uma diminuição na contagem deste microrganismo dos 15 aos 45 dias e, após este período, houve um aumento na sua população (MELO et al., 2013).

Staphylococcus aureus foi encontrado em contagens médias de $1,1 \times 10^{3}$ UFC.g. $g^{-1}$ em QMA do Serro (SANTOS, 2010). Contagens superiores deste microrganismo foram relatadas em QMA de Araxá, em que os

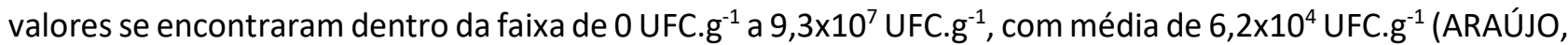
2004).

\section{Coliformes totais e termotolerantes}

Com relação aos níveis de contaminação por coliformes totais todos os queijos com o tempo 0 dias de maturação (4 amostras/12 repetições) apresentaram cepas de coliformes (Tabela 3). Porém o resultado de $1,1 \times 10^{3} \mathrm{NMP} \cdot \mathrm{g}^{-1}$ encontrado é bem abaixo do máximo tolerado pela legislação de $5 \times 10^{3} \mathrm{NMP} \cdot \mathrm{g}^{-1}$ para queijos com alta umidade <46\% (MINAS GERAIS, 2008; BRASIL, 2001). Conclui-se que mesmo no tempo 0 dias para coliformes totais, o Queijo Minas Artesanal do Triângulo Mineiro enquadra nos parâmetros exigidos pela legislação vigente, sendo próprio para o consumo humano.

Os coliformes a $30^{\circ} \mathrm{C}$ em altas contagens são responsáveis pela deterioração do queijo levando a um defeito clássico chamado estufamento precoce. Este defeito é observado entre o processo de elaboração e o processo de salga do queijo, sendo perceptível, logo, nas primeiras 24 horas de produção. A lactose do queijo é fermentada pelas bactérias do grupo coliformes, levando a formação de ácido lático, ácido acético e etanol, que conferem um sabor picante, ligeiramente amargo ao queijo, e também há produção de $\mathrm{CO}_{2} \mathrm{e}$ $\mathrm{H}_{2}$, gases responsáveis pela formação de olhaduras pequenas no produto final, em coliformes 
termotolerantes (CASTRO, 2015). Das 16 amostras analisadas, nenhuma se encontrava estufada, abauladas, porém ao corte apresentavam micro-olhaduras características típicas deste tipo de defeito.

Os coliformes a $45^{\circ} \mathrm{C}$, principalmente, representados por Escherichia coli, fazem parte da microbiota intestinal de animais de sangue quente, incluindo o homem. Sua presença no queijo pode indicar, além de falhas no processo de higienização durante o processamento do QMA, presença de material de origem fecal e de outros microrganismos enteropatogênicos. Desta forma, além de causarem a deterioração do queijo, algumas cepas são comprovadamente patogênicas ao homem e aos animais (JAY et al., 2005; TRABULSI et al., 2008).

Tabela 3: Número Mais Provável (NMP) de coliformes totais nos Queijos Minas Artesanais nas queijarias visitadas

\begin{tabular}{cc}
\hline QUEIJARIA & Coliformes Totais (NMP.g-1) \\
\hline A0* & $2,3 \times 10^{1}$ \\
BO* $^{-1}$ & $2,3 \times 10^{1}$ \\
C0* & $9,3 \times 10^{1}$ \\
D** & $1,1 \times 10^{3}$ \\
\hline
\end{tabular}

*0 dias de maturação.

Soares (2014) relatou em sua pesquisa na região do Triângulo Mineiro que os números de coliformes totais foram acentuadamente reduzidos aos cinco dias de maturação em temperatura ambiente, mas já aos três dias, atingiu os padrões preconizados pela legislação, que é de no máximo $5 \times 10^{3} \mathrm{UFC} . \mathrm{g}^{-1}$ para coliformes termotolerantes, segundo a Legislação Estadual (MINAS GERAIS, 2008). Este período de maturação, suficiente para a redução a níveis aceitáveis de coliformes totais só foi observado ao final de sete semanas por Santos (2010). Já Martins (2006) verificou que eram necessários seis dias para a redução das contagens.

Com relação aos níveis de contaminação por coliformes totais em 127 amostras de queijo coalho analisados, $56(44,1 \%)$ não apresentaram crescimento deste microrganismo, 15 (11,8\%) apresentaram contagem entre $10^{1}$ UFC. $g^{-1}$ e $5 \times 10^{2}$ UFC. $g^{-1}$ e $56(44,1 \%)$ tinham mais de $5 \times 10^{2}$ UFC.g $g^{-1}$ (DUARTE et al., 2005).

Com relação aos níveis de contaminação por coliformes termotolerantes todos os queijos com o tempo 0 dias de maturação ( 4 amostras $/ 12$ repetições) apresentaram contaminação. Porém com o resultado de $2,3 \times 10^{1} \mathrm{NMP} . \mathrm{g}^{-1}$, pode-se considerar permitido para o consumo humano, já que está abaixo do máximo tolerado pela legislação de $5 \times 10^{2} \mathrm{NMP}^{-1}{ }^{-1}$ para queijos com alta umidade <46\% (MINAS GERAIS, 2008; BRASIL, 2001). Conclui-se que no tempo 0 dias para coliformes termotolerantes, o Queijo Minas Artesanal do Triângulo Mineiro enquadra nos parâmetros exigidos pela legislação vigente, sendo próprio para o consumo humano sem danos à saúde.

Uma observação a se destacar foi que todos os queijos analisados com mais de 10 dias de maturação não apresentaram contaminação nem para coliformes totais, tão pouco para termotolerantes, somente as amostras com 0 dias, conforme Figura 5. Com exceção da queijaria D que não apresentou coliformes termolerantes em nenhum tempo de maturação, os outros apresentaram uma média de $2,3 \times 10^{1} \mathrm{NMP.g}$ ${ }^{1}$ (Tabela 4).

Tabela 4: Valores obtidos para de coliformes termotolerantes nos Queijos Minas Artesanais nas queijarias analisadas. QUEIJARIA Coliformes Termotolerantes 


\begin{tabular}{lc}
\hline BO* & $2,3 \times 10^{1}$ \\
CO* $^{*}$ & $2,3 \times 10^{1}$ \\
DO* & $<3$ \\
\hline
\end{tabular}

*0 dias de maturação.

Soares (2014) em sua pesquisa com o Queijo Minas Artesanal em Uberlândia/MG mostrou que apesar da redução acentuada das contagens médias de $E$. coli aos cinco dias de maturação, somente após 12 dias, as contagens atingiram o padrão legal exigido, que é de no máximo $10^{2}$ UFC.g-1 (MINAS GERAIS, 2008).

Trinta e duas amostras $(80 \%)$ apresentaram coliformes a $35^{\circ} \mathrm{C}$ acima do permitido na legislação em Queijo Minas Artesanal do Serro. Neste mesmo estudo, vinte e quatro amostras (60\%) apresentaram coliformes a 45 ㅇ C acima de $5 \times 10^{3}$ UFC. $g^{-1}$ (BRANT et al., 2007). Em queijos artesanais comercializados em feiras livres de Uberlândia/MG as contagens de coliformes totais variaram de $5 \times 10^{1} \mathrm{NMP} \cdot \mathrm{g}^{-1}$ a 1,6 $\times 10^{5} \mathrm{NMP} \cdot \mathrm{g}^{-}$ ${ }^{1}$, enquanto que as de coliformes termotolerantes ficaram entre $2 \times 10^{1} \mathrm{NMP}^{-g^{-1}}$ a $1,6 \times 10^{4}$ NMP.g-1 (REZENDE et al., 2010).

Em QMA de Araxá, as contagens de coliformes a $30^{\circ} \mathrm{C}$ e Escherichia coli variaram de 0 UFC. $\mathrm{g}^{-1} \mathrm{a}$ $3,2 \times 10^{6}$ UFC. $g^{-1}$, com média de $1,5 \times 10^{4}$ UFC. $g^{-1}$, e de 0 UFC.g ${ }^{-1}$ a $1,7 \times 10^{6}$ UFC. $g^{-1}$, com média de $10^{3}$ UFC. $g^{-1}$, respectivamente (ARAÚJO, 2004). Contagens inferiores foram encontradas em queijo do Serro, em que coliformes a $30^{\circ} \mathrm{C}$ resultaram em contagens médias de $4,4 \times 10^{3}$ UFC.g ${ }^{-1}$ e Escherichia coli de $1,7 \times 10^{2} \mathrm{UFC}^{-g^{-1}}$ (SANTOS, 2010).

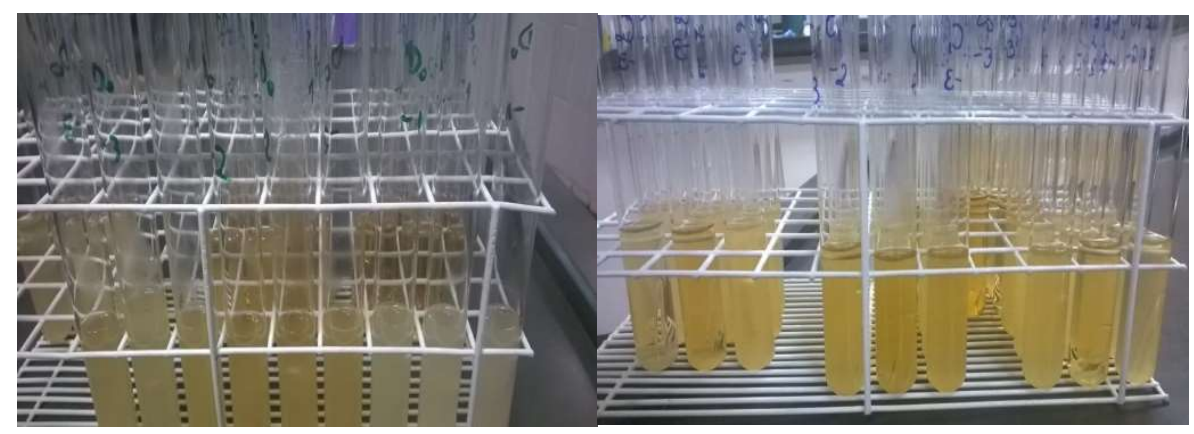

Figura 5: Análise de Coliformes Totais e Termotolerantes.

\section{Salmonella spp.}

A contaminação do Queijo Minas Artesanal por Salmonela spp. pode ocorrer devido ao controle inadequado de temperatura, manipulação incorreta ou contaminação cruzada. Estudos em queijos contaminados por Salmonella spp. demonstram a capacidade destas bactérias de se manterem viáveis por longo período, o que ressalta a importância do controle de qualidade microbiológica do produto, visto que a legislação brasileira estabelece ausência desta bactéria em alimentos (CASTRO, 2015).

A pesquisa aqui exposta, a Salmonella spp. não foi evidenciada em nenhuma das 48 análises (Figura 06). Conclui-se que todas as amostras estavam dentro do padrão exigido na legislação.

Em contrapartida a este estudo, um trabalho com queijo maturado, sob refrigeração, do Serro, uma de oito amostras, no período das águas, apresentou Salmonella spp. aos 8 e 15 dias de maturação. Aos 22 dias, Salmonella spp. não foi mais isolada (MARTINS, 2006). De forma semelhante, Salmonella sp. foi verificada em uma das 20 amostras de Queijos Minas Frescais comercializado na cidade de Uberlândia - MG 
(GRANDI et al., 2006).

Sousa et al. (2006) encontraram 30\% das amostras positivas para Salmonella spp. em Queijos Minas Meia Cura informais vendidos na cidade de Jacareí-SP. Em trabalho semelhante a bactéria foi detectada em 9\% das amostras de Queijo de Coalho e em 15\% das de Queijo de Manteiga produzidos no estado do Rio Grande do Norte (FEITOSA et al., 2003). Em estudo realizado em Queijos de Coalho, produzidos e comercializados no estado de Pernambuco, 5,5\% das 127 amostras analisadas foram positivas para Salmonella spp. (DUARTE et al., 2005).

Com resultados semelhantes ao deste estudo, nenhuma amostra de queijo apresentou contaminação por Salmonella spp. em análise de QMA do Serro (BRANT et al., 2007), QMA de Araxá (ARAÚJO, 2004), QMA de Campo das Vertentes (OLIVEIRA, 2010) e QMA comercializado em feiras livres (REZENDE et al., 2010).

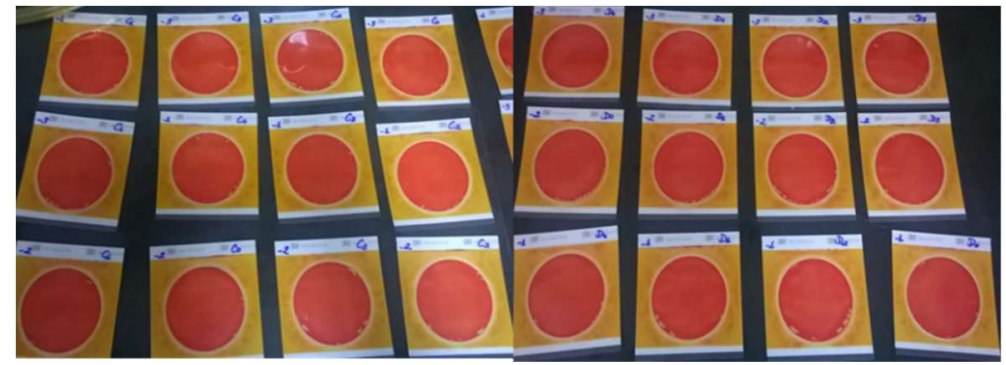

Figura 6: Petrifilm das análises de Salmonella spp.

\section{Listeria monocytogenes}

No Brasil e em outros países em desenvolvimento, além da falta de preocupação por parte das autoridades de saúde pública em relação à sua disseminação, não há estatísticas oficiais de casos de listeriose, pois sua notificação não é de caráter obrigatório. Este fato pode justificar a baixa incidência reportada no país. Entretanto, a listeriose representa relevante risco à saúde pública, pela severidade das sequelas e do alto índice de mortalidade em populações de risco ( $20 \%$ a 30\%), como indivíduos imunocomprometidos, idosos e gestantes (CRUZ et al., 2008).

No presente trabalho, quatro amostras de queijo apresentaram suspeita de Listeria monocytgenes. Porém a única confirmação realizada foi do gênero, sendo Listeria spp. (Tabela 5).

Tabela 5: Valores obtidos para Listeria spp. nos Queijos Minas Artesanais nas queijarias analisadas.

\begin{tabular}{cccc}
\hline Queijaria & Tempo de maturação & Diluição & Listeria spp. \\
\hline A & 0 dias & -1 & 5 colônias \\
\hline \multirow{2}{*}{ B } & 0 dias & -1 & 6 colônias \\
& 10 dias & -1 & 5 colônias \\
\end{tabular}

Constata-se na pesquisa que a presença de Listeria spp. no Queijo Minas Artesanal de Monte Carmelo/MG está em desacordo com a legislação vigente, que não tolera a presença de quaisquer espécies de microrganismos patogênicos, no item alimentar. As colônias típicas de Listeria spp. foram submetidas à coloração de gram para confirmação de gram-positivas, além de sua forma em bastonetes e com flagelos. $O$ resultado resultou na confirmação do gênero Listeria spp. nas amostras. Após essa etapa não houve 
confirmação da espécie monocytogenes.

Em nenhuma amostra de queijo apresentou contaminação por Listeria monocytogenes. Em análise de QMA do Campo das Vertentes (CASTRO, 2015), QMA de Araxá (ARAÚJO, 2004), QMA de Campo das Vertentes (OLIVEIRA, 2010) e QMA comercializado em feiras livres (REZENDE et al., 2010). Mata (2009) não isolou L. monocytogenes em nenhuma das 48 amostras Queijos Minas Artesanal (um tipo minas com cura curta) provenientes da região do Serro (MG), assim como Velloso et al. (2003) em queijo minas Araxá.

Ao contrário das pesquisas anteriores, Raimundo (2013), encontrou das 165 amostras analisadas, 53 apresentaram colônias suspeitas de Listeria spp. nos ágares Palcam ou Oxford. De cada uma dessas 53 amostras, 5 colônias foram purificadas em TSA, totalizando 265. Das 265 colônias, 103 foram classificadas como gênero Listeria pelas provas: motilidade, redução de nitrato, catalase e gram. Das 103, somente 11 foram confirmadas como Listeria monocytogenes pelo exame de Proteína-C Reativa (PCR).

Como já citado, de maneira geral a ocorrência do agente em queijos no Brasil é baixa, mas a literatura ressalta que diversos autores encontraram altas populações de coliformes nos produtos analisados e sugerem que a baixa ocorrência de L. monocytogenes em queijos pode ser resultado das altas populações de coliformes presentes nesses produtos, por competirem com a Listeria no alimento e interferirem no isolamento do patógeno (RAIMUNDO, 2013).

\section{CONCLUSÕES}

Os resultados microbiológicos, foram identificadas contagens toleráveis de Staphylococcus aureus, estando dentro dos padrões permitidos pela RDC nำ12/2001, de no máximo $10^{3} \mathrm{NMP} / \mathrm{g}$, já o Staphylococcus spp. apresentou um alto número nas placas, porém não há parâmetros que determinem o máximo tolerável. A análise de Salmonella resultou na ausência da bactéria em todas as amostras, em contrapartida o estudo sobre a Listeria resultou na sua presença em 6 amostras, porém não foi confirmada como Listeria monocytogenes, corroborando para a influência do período de maturação sobre as contagens de bioindicadores e presença de patógenos.

Logo, este estudo demonstrou que o período de maturação em que as amostras de Queijo Minas Artesanal apresentaram conformidade com a legislação vigente foi de no mínimo 10 dias. Logo, há necessidade de estabelecer novos períodos para comercialização dos mesmos, de forma a garantir a segurança do consumidor e as características do queijo. Este estudo colabora para outros serem realizados tanto pela EMATER quanto IMA. Este seria, então, o primeiro passo para a definição do período de maturação ideal para que o Queijo Minas Artesanal da região se adeque aos pressupostos de um alimento seguro.

Fazem-se necessários incentivos tanto na esfera Municipal quanto Estadual para contínuo desenvolvimento da Região Triângulo Mineiro como produtora de QMA, bem como para a melhoria dos queijos nela produzidos, de maneira a oferecer à população e a sua gama de turistas um produto seguro e de qualidade microbiológica que atenda a legislação vigente e com características sensoriais únicas. 


\section{REFERÊNCIAS}

AMVAP. Associação dos Municípios da Microrregião do Vale do Paranaíba. Triângulo é reconhecido como 6a região produtora do Queijo Minas Artesanal. AMVAP, 2014.

AOAC. Association of Official Analytical Chemists. Official Methods of Analysis of the AOAC. 18 ed. Gaithersburg: AOAC, 2005.

ARAÚJO, R. A. B. M.. Diagnóstico socioeconômico, cultural e avaliação dos parâmetros físico-químicos e microbiológicos do Queijo Minas Artesanal da região de Araxá. Dissertação (Mestrado em Ciência e Tecnologia de Alimentos) Universidade Federal de Viçosa, Viçosa, 2004.

BRANT, L. M. F.; FONSECA, L. M.; SILVA, M. C. C.. Avaliação da qualidade microbiológica do Queijo Minas Artesanal do Serro-MG. Arquivo Brasileiro de Medicina Veterinária e Zootecnia, v.59, n.6, p.1570-1574, 2007.

BRASIL. Ministério da Saúde Agência Nacional de Vigilância Sanitária. Resolução da Diretoria Colegiada N. 12, de 2 de janeiro de 2001. Regulamento técnico sobre os padrões microbiológicos para alimentos., Brasília: DOU, 2001.

CASTRO, R. D.. Queijo Minas Artesanal fresco de produtores não cadastrados da mesorregião de Campo das Vertentes MG: qualidade microbiológica e físico-química em diferentes épocas do ano. Dissertação (Mestrado em Ciência Animal) - Universidade Federal de Minas Gerais, Belo Horizonte, 2015.

CHALITA, M.A.N.; SILVA, R. O.P; PETTI, R. H. V.; SILVA, C. R. L.. Algumas considerações sobre a fragilidade das concepções de qualidade no mercado de queijos no Brasil. São Paulos: IEA, 2009.

CRUZ, C. D.; MARTINEZ, M. B.; DESTRO, M. T.. Listeria monocytogenes: um agente infeccioso ainda pouco conhecido no Brasil. Alim. Nutr. Araraquara, v.19, n.2, p.195-206, 2008.

DINIZ, M. F. S.. Queijo Canastra: um estudo envolvendo aspectos culturais e parâmetros de inocuidade do alimento. Dissertação (Mestrado em Ciências) - Universidade de São Paulo, Piracicaba, 2013.

DORES, M. T.; FERREIRA, C. L. L. F.. Queijo Minas Artesanal, tradição centenária: Ameaças e Desafios. Revista Brasileira de Agropecuária Sustentável, v.2, n.2, p.26-34, 2012.

DUARTE, D. A. M.; SCHUCH, D. M. T.; SANTOS, S. B.. Pesquisa de Listeria monocytogenes e microrganismos indicadores Higiênico-sanitários em queijo de coalho produzido e comercializado no estado de Pernambuco. Arq. Inst. Biol., v.72, n.3, p.297-302, 2005.

EMATER. Empresa de Assistência Técnica Rural de Minas Gerais. Serro, Medeiros e Sabinópolis são recordistas no cadastro de produtores do Queijo Minas Artesanal. Belo Horizonte: EMATER, 2015.

FALCONI, V.. Controle da qualidade total (no estilo japonês). Belo Horizonte, 2003.

FEITOSA, T.; BORGES, M. F.; NASSU, R. T.; AZEVEDO, É, H. F.;
MUNIZ, C. R.. Pesquisa de Salmonella sp., Listeria sp. e microrganismos indicadores higiênico-sanitários em queijos produzidos no estado do Rio Grande do Norte. Ciênc. Tecnol. Aliment., v.23, p.162-165, dez. 2003.

GRANDI, A. Z.; ROSSI, D. A.. Qualidade microbiológica do queijo minas frescal comercializado na cidade de Uberlândia-MG. In: ENCONTRO INTERNO DE INICIAÇÃO CIENTÍFICA, 6. Anais. Uberlândia, 2006.

IMA. Instituto Mineiro de Agropecuária. Portaria n. 517, de 14 de junho de 2002: Estabelece normas de defesa sanitária para rebanhos fornecedores de leite para produção de queijo Minas artesanal. Portaria n. 518, de 14 de junho de 2002: Dispõe sobre requisitos básicos das instalações, materiais e equipamentos para a fabricação do queijo Minas artesanal. Portaria n. 523, de 3 de julho de 2002: Dispõe sobre as condições higiênico-sanitárias e Boas Práticas na Manipulação e Fabricação do Queijo Minas Artesanal. Belo Horizonte: IMA, 2002.

IMA. Instituto Mineiro e Agropecuária. Agricultura Familiar Mineira é treinada em boas práticas de fabricação. Instituto Mineiro de Agropecuária. Belo Horizonte: IMA, 2014.

IPHAN. Instituto do Patrimônio Histórico e Artístico Nacional. Processo n. 01450.012192/2006-65: Parecer do processo de Registro de Patrimônio Imaterial Modo Artesanal de fazer Queijo de Minas, nas regiões do Serro e das serras da Canastra e do Salitre, MG. Brasília: IPHAN, 2006.

JAY, J. M.. Microbiologia moderna dos alimentos. 6 ed. Porto Alegre: Artmed, 2005.

LUBECK, G. M.; LARA, J. A. F.; BAGATINI, L.. Avaliação de algumas características físico-químicas e microbiológicas de algumas marcas de queijo tipo colonial produzido no sudoeste do estado do Paraná. Rev. Inst. Lat. Cândido Tostes, v.56, p.185-193, 2001.

MARTINS, J. M.. Características físico-químicas e microbiológicas durante a maturação do queijo Minas artesanal da Região do Serro. Tese (Doutorado em Ciência e Tecnologia de Alimentos). Viçosa: UFV, 2006.

MATA, G. M. S. C.. Comparação de métodos para pesquisa de Salmonella sp. e Listeria sp. e avaliação microbiana e físico química em queijos minas artesanal. Dissertação (Mestrado em Ciências) - Universidade Federal de Viçosa, Viçosa, 2009.

MELO, F. D.; DALMINA, K. A.; PEREIRA, M. N.; RAMELLA, M. V.; THALER NETO, A.; VAZ, E. K.; FERRAZ, S. M.. Avaliação da inocuidade e qualidade microbiológica do queijo artesanal serrano e sua relação com as variáveis físico químicas e o período de maturação. Acta Scientiae Veterinariae, v.41, n.1152, 2013.

MINAS GERAIS. Assembleia Legislativa do Estado de Minas Gerais. Decreto n. $\mathbf{4 4 . 8 6 4}$ de 01 de agosto de 2008. Altera o regulamento da lei n. 14.185 de 31 de janeiro de 2002, que dispõe sobre o processo de produção do queijo de minas artesanal. Belo Horizonte: DOE, 2008. 
MINAS GERAIS. Assembleia Legislativa do Estado de Minas Gerais. Lei n. 14.185, de 31 de janeiro de 2002. Dispõe sobre o processo de produção do queijo Minas artesanal e dá outras providências. Belo Horizonte: DOE, 2002.

MINAS GERAIS. Governo do Estado de Minas Gerais. Lei n. $\mathbf{2 0 5 4 9}$ de 18 de dezembro de 2012. Dispõe sobre a produção e a comercialização dos queijos artesanais de Minas Gerais. Revoga a Lei n. 14.185 de 31 de janeiro de 2002. Belo Horizonte: DOE, 2012.

PICOLI, S. U.; BESSA, M. C.; CASTAGNA, S. M. F.; GOTTARDI, C. P. T.; SCHMIDT, V.; CARDOSO, M.. Quantificação de coliformes, Staphylococcus aureus e mesófilos presentes em diferentes etapas da produção de queijo frescal de leite de cabra em laticínios. Ciência e Tecnologia de Alimentos, v.26, p.64-69, 2006.

RAIMUNDO, D. C.. Listeria Monocytogenes em queijo minas meias cura: análise quantitativa, qualitativa e perfil molecular das cepas isoladas. Tese (Doutorado em Ciências) - Universidade de São Paulo, São Paulo, 2013.

RESENDE, M. F. S.. Queijo Minas artesanal da Serra da Canastra: influência da altitude e do nível de cadastramento das queijarias nas características físico-químicas e microbiológicas. Rev. Inst. Latic. 'Cândido Tostes', v.65, n.377, p.36-42, 2010.

REZENDE, P. H. L.; MENDONÇA, E. P.; MELO, R. T.; COELHO, L. R.; MONTEIRO, G. F.; ROSSI, D. A.. Aspectos Sanitários do Queijo Minas Artesanal comercializado em feiras livres.
Revista do Instituto de Laticínios Cândido Tostes, Juiz de Fora, v.65, n.377, p.36-42, 2010.

SANTOS, A. S.. Queijo minas artesanal da microrregião do Serro-MG: efeito da sazonalidade sobre a microbiota do leite cru e comportamento microbiológico durante a maturação. Dissertação (Mestrado em Zootecnia) Universidade Federal dos Vales do Jequitinhonha e Mucuri, Diamantina, 2010.

SOARES, D. B.. Caracterização físico-química e microbiológica do queijo Minas Artesanal na região de Uberlândia-MG. Dissertação (Mestrado em Ciências Veterinárias) - Universidade Federal de Uberlândia, Uberlândia, 2014.

SOUSA, D. D. P.; GUIMARÃES, R.; VILLELA, F. R. M. A MENDES, H. M. F.; OLIVEIRA, N. S. P.; TUCCI, T. M.; BRAGA, M. C.; BALIAN, S. C.; TELLES, E. O.. Avaliação da qualidade higiênico-sanitária de queijo Minas frescal e meia crua comercializados de forma informal em Jacareí-SP. Revista Brasileira de Vigilância Sanitária, v.2, n.1, p. 60-63, 2006.

TRABULSI, L. R.; ALTERTHUM, F.. Microbiologia. 5 ed. São Paulo: Atheneu, 2008.

VELLOSO, C. R. V.; XAVIER, E.; GUSMÃO, M. D.; LOPES, A. C. F.; MELO, C. A.; PENA, L. A.; SILVEIRA, L. A.; CAETANO, J. L. V.. Avaliação da composição e da qualidade microbiológica dos queijos Minas Araxá, do Serro e Canastra. Higiene Alimentar, São Paulo, v.17, n.101-105, 2003.

A CBPC - Companhia Brasileira de Produção Científica (CNPJ: 11.221.422/0001-03) detém os direitos materiais desta publicação. Os direitos referem-se à publicação do trabalho em qualquer parte do mundo, incluindo os direitos às renovações, expansões e disseminações da contribuição, bem como outros direitos subsidiários. Todos os trabalhos publicados eletronicamente poderão posteriormente ser publicados em coletâneas impressas sob coordenação da Sustenere Publishing, da Companhia Brasileira de Produção Científica e seus parceiros autorizados. Os (as) autores (as) preservam os direitos autorais, mas não tem permissão para a publicação da contribuição em outro meio, impresso ou digital, em português ou em tradução. 